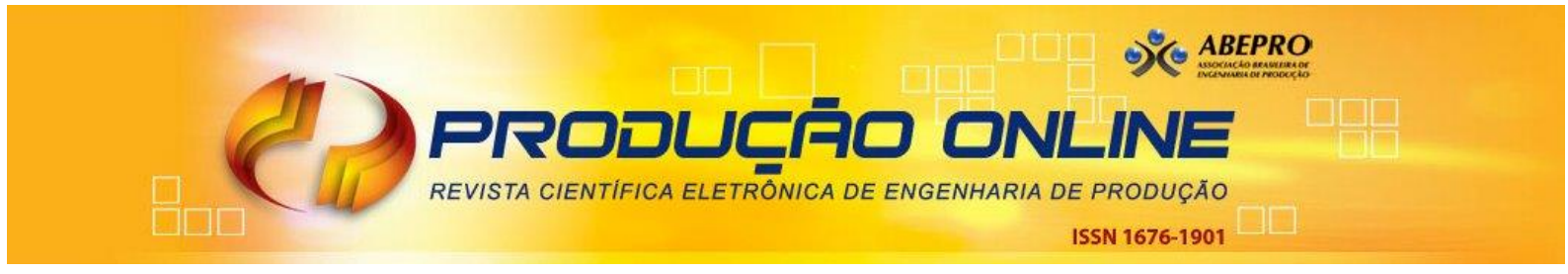

\title{
APLICAÇÃO DA METODOLOGIA SEIS SIGMA PARA MELHORIA CONTÍNUA DA QUALIDADE EM UMA INDÚSTRIA ALIMENTÍCIA
}

\section{APPLICATION OF THE SIX SIGMA METHODOLOGY FOR CONTINUOUS IMPROVEMENT QUALITY IN A FOOD INDUSTRY}

\author{
Marcos Meurer da Silva* E-mail: marcosmeurerdasilva@gmail.com \\ Carlos Eduardo Soares Camparotti* E-mail: carloscamparotti@ufgd.edu.br \\ Lorena Mazia Enami* E-mail: Iorenaenami@gmail.com \\ Karoline Guedes* E-mail: karolineguedes13@gmail.com \\ Beatriz Lavezo dos Reis* E-mail: bia.lavezo@gmail.com \\ Thiago de Souza Borges Ordeno*E-mail: thiagoordeno@gmail.com \\ *Universidade Estadual de Maringá (UEM), Maringá, PR \\ **Universidade Federal da Grande Dourados (UFGD), Dourados, MS
}

Resumo: A competitividade entre as empresas exige que busquem por alternativas não só na garantia por produtos melhores aos clientes, mas também no que se refere ao processo produtivo sem desperdícios e elevados custos. O presente trabalho apresenta a implementação da metodologia Seis Sigma como meio de obtenção de melhores resultados na qualidade do processo produtivo e como uma mudança organizacional para com a resolução de problemas. A pesquisa foi realizada através de um estudo de caso, na qual foram coletados dados e informações pertinentes para a proposição e implantação de melhorias. O modelo DMAIC foi utilizado para a coordenação das etapas, assim como a utilização de ferramentas da qualidade dentro de cada uma das etapas. Destaca-se a obtenção de resultados satisfatórios com relação a eliminação do problema do peso do presunto fora da especificação, a elevação do nível sigma de 1,16 para 3,24 , bem como, o conhecimento fornecido a todos os colaboradores do setor sobre a importância de realizar melhorias, ficam como um primeiro passo para a mudança do setor.

Palavras-chave: Seis Sigma. Melhoria Contínua. Modelo DMAIC. Nível Sigma. Qualidade.

\begin{abstract}
Competitiveness between companies requires that they look for alternatives not only in guaranteeing better products for customers, but also with regard to the production process without waste and high costs. This paper presents the implementation of the Six Sigma methodology as a means of obtaining better results in the quality of the production process and as an organizational change towards problem solving. The research was carried out through a case study, in which data and relevant information were collected for the proposition and implementation of improvements. The DMAIC model was used to coordinate the stages, as well as the use of quality tools within each stage. It is noteworthy that satisfactory results were obtained in relation to the elimination of the ham weight problem out of specification, the increase in the sigma level from 1.16 to 3.24 , as well as the knowledge provided to all employees in the sector about the importance of making improvements, remain as a first step towards changing the sector.
\end{abstract}

Keywords: Six Sigma. Continuous Improvement. Methodology DMAIC. Sigma Level. Quality.

\section{INTRODUÇÃO}

O cenário empresarial no mundo globalizado e o advento de novas tecnolo- 
gias traz uma constante necessidade de maior competitividade, já que a concorrência aumenta consideravelmente. Isso remete as indústrias a busca por melhoria em processos de produção, redução de desperdícios e custos, melhoria nas técnicas de vendas para que possam alcançar além da sobrevivência no mercado, mas também o alcance dos objetivos traçados.

Com a finalidade de atender as exigências do mercado e superá-las, as organizações têm ampliado cada vez mais o conceito de qualidade como um fator primordial para a competitividade. Isso porque a gestão da qualidade permite melhorar os processos e produtos e possibilitar uma busca coerente pelos resultados.

Diante dessa perspectiva, a indústria alimentícia, mais precisamente o setor de alimentos processados a partir da carne suína e bovina merece destaque devido a sua característica de instabilidade no preço da matéria-prima in natura e, portanto, há grande variações nos custos dos produtos. Desta maneira, o foco na melhoria da qualidade do produto, assim como no processo produtivo é extremamente necessário.

Para Slack et al. (2009) é necessário constantemente buscar a melhoria dos processos, porém, ressaltam que o importante não é propriamente o impacto de cada melhoria apresenta no sistema, mas sim o pensamento de estar sempre em busca de melhorar.

Nesse contexto, existem metodologias e ferramentas que auxiliam os gestores na busca por níveis de qualidade sempre maiores. De acordo com Werkema (2014) o modelo Seis Sigma tem se mostrado uma destas importantes metodologias utilizadas para a concentração de esforços na melhoria de processos, onde o objetivo é obter ganhos sejam financeiros ou mesmo de qualidade dos produtos, além de reduzir custos e aumentar a eficiência produtiva. As ferramentas utilizadas por tal metodologia em grande parte são as mesmas que são utilizadas nos sistemas de qualidade, entretanto, um projeto Seis Sigma bem estruturado consegue entregar resultados potencializados devido aos objetivos de melhoria estarem diretamente vinculados com as metas financeiras da empresa (ROTONDARO, 2008).

Em qualquer indústria o reprocesso de produtos sejam eles acabados ou não representa um alto impacto nos custos da organização, ainda mais se considerar 
indústrias de grande porte com diversos setores internos e um grande mix de produtos. Desta maneira, a metodologia Seis Sigma pode auxiliar nesse processo de redução de desperdícios e diminuição dos custos com reprocesso.

No entanto, para o sucesso da aplicação da metodologia Seis Sigma é necessário que haja suporte de diferentes partes da organização, já que há o desprendimento de recursos humanos e financeiros em prol dos objetivos. Assim, qualquer tamanho de empresa é imprescindível o engajamento de toda a organização, além da correta definição da equipe responsável pelo gerenciamento das atividades. Além disso, cabe ressaltar a necessidade de mostrar que os resultados são alcançáveis e que a melhoria da qualidade, redução de custos e aumento da produtividade pode proporcionar um ganho global para a organização e colaboradores.

Desta maneira, faz-se necessário uma mudança para com a qualidade, principalmente entre os colaboradores do chão de fábrica que estão envolvidos diretamente com as operações da produção, visto que, culturalmente há um baixo incentivo e autonomia dos colaboradores para a resolução de problemas (CARPINETTI, 2012).

O objetivo deste trabalho é aplicar a metodologia Seis Sigma para a redução de reprocesso de presunto em uma indústria de alimentos processados, por meio de um estudo de caso, utilizando o modelo DMAIC para solucionar o problema, além de propiciar uma mudança cultural do setor para com a qualidade.

\section{REVISÃO BIBLIOGRÁFICA}

\subsection{História da metodologia Seis Sigma}

Na década de 70 quando houve a crise dos combustíveis no Estados Unidos o conceito de qualidade passou a ser impulsionado pela necessidade de os produtos americanos obterem uma qualidade superior aos japoneses que até então conquistava o mercado consumidor (ECKES, 2001).

Conforme o mesmo autor, os japoneses tinham uma metodologia de trabalho diferente que os americanos. Enquanto que os primeiros prezavam pela qualidade em todas as etapas do processo, os americanos tinham a prática de inspeção apenas no final da linha de produção. Assim, várias empresas americanas foram ao 
Japão para entender como eram aplicados os métodos de produção que garantiam produtos com melhores qualidades e uma produtividade ascendente.

Em 1985, a empresa americana Motorola deu início ao programa Seis Sigma. A empresa ao analisar seus processos constatou que havia grande variabilidade no processo produtivo que culminava em grandes custos para a organização. Bob Galvin foi um dos precursores do Seis Sigma na Motorola, o mesmo relatou a criação do programa:

\begin{abstract}
Muito antes de pensarmos no Seis Sigma, fizemos uma reunião de executivos. Nessa ocasião Art Sundy, diretor da área de rádios bidirecionais, declarou: 'Nossa qualidade é nojenta'. Tínhamos $85 \%$ do market share mundial e estávamos conseguindo um crescimento de dois dígitos. A despeito disso, todos nós diretores levamos Sundy a sério. Rapidamente percebemos que, se conseguíssemos controlar a variação na produção, poderíamos fazer funcionar todas as peças e processos e alcançar um resultado final de 3,4 defeitos por milhão de oportunidades, ou seja, um nível Seis Sigma. Nosso pessoal cunhou o termo e ele 'pegou'. Era prático, pois as pessoas entendiam que, quando se consegue controlar a variação, é possível obter resultados notáveis." (MANAGEMENT, 2006).
\end{abstract}

A partir de então, o programa se consolidava na empresa e em pouco tempo passou a ser usado também em outras empresas que entenderam que a variabilidade do processo causava grande custos de produção e que já não bastava atender as especificações dos produtos.

\title{
2.2 Seis Sigma
}

A metodologia Seis Sigma refere-se a uma abordagem constituída de um conjunto de práticas que visam a melhoria contínua de um processo ou produto. Trata-se não só de um conceito estatístico de controle de processo, mas também de uma filosofia que a empresa pode buscar para a redução de custos nos processos produtivos. Ainda, de uma maneira mais ampla, procura sistematizar a obtenção de resultados positivos na produtividade e eficiência da empresa (BETTS et al., 2013).

De acordo com Harry (1998), o Seis Sigma pode ser visto como uma ferramenta gerencial para a organização em busca de melhoria seja nos processos ou produtos, podendo até mesmo ser aplicada em serviços.

Para Werkema (2014):

Seis Sigma é uma estratégia gerencial disciplinada e altamente quantitativa, 
que tem como objetivo aumentar expressivamente a performance e a lucratividade das empresas, por meio da qualidade de produtos e processos e do aumento da satisfação de clientes e consumidores.

A metodologia Seis Sigma abrange uma mudança de cultura organizacional quanto a qualidade nos processos e produtos. Isso porque não é apenas um modelo de métodos estatísticos, mas também de filosofia na busca da melhoria contínua. O modelo piramidal, conforme é apresentado na Figura 1, mostra que há o embasamento dados numéricos e estatísticos, porém é necessário o apoio da alta direção para o alcance dos resultados (NICOLETTI JÚNIOR, 2007, p.15).

Figura 1 - Estratégia Seis Sigma

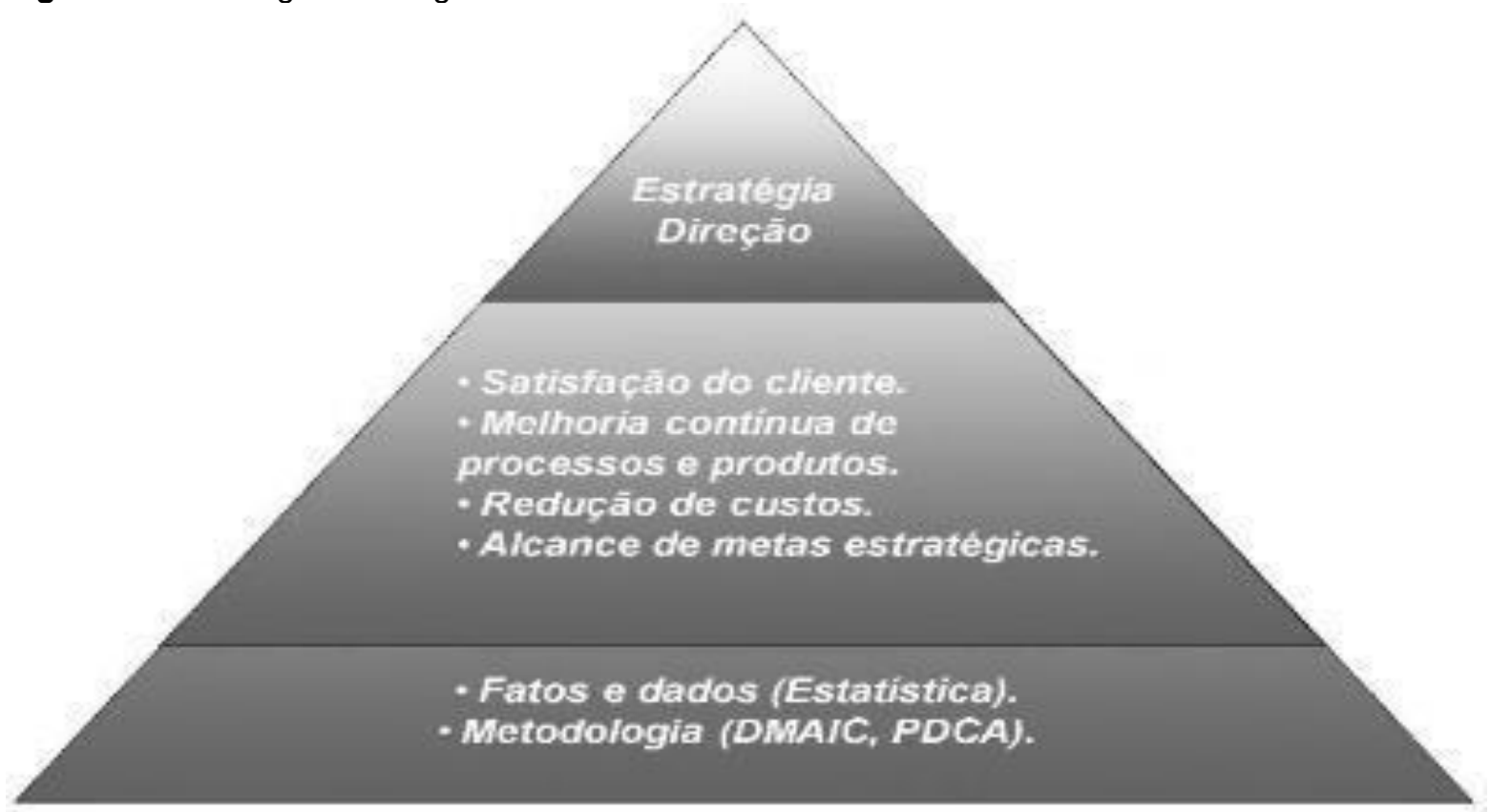

Fonte: Nicoletti Junior (2007, p.15)

Essa metodologia recebeu esse nome devido ao fato do "sigma" representar o desviopadrão de um processo, isto é, a capacidade de um processo produtivo e também pela habilidade de tal processo produzir peças não defeituosas. Cabe ressaltar ainda, que a sigma, na estatística refere-se a uma medida de variação chamada de desvio-padrão (KLEFSJO, 2001).

Para Bets et al. (2013) o nível sigma $(\sigma)$ pode também ser representado em termos de "Defeitos Por Milhão de Oportunidades (DPMO)". O Quadro 1 mostra a relação entre o nível sigma, defeitos por milhão de oportunidades, a conformidade e o custo da não qualidade devido aos produtos não conformes. A medida que se eleva o nível sigma, o percentual de conformidade aumenta e, consequentemente, o 
número de defeitos por milhão diminui, além de o custo que a empresa tem com a não qualidade do produto diminui.

Quadro 1 - Impacto do nível sigma o para a organização

\begin{tabular}{|c|c|c|c|}
\hline Nível (б) de Qualidade & Conformidade (\%) & Defeitos por Milhão & $\begin{array}{c}\text { Custo da Não Qualidade (\% } \\
\text { faturamento da empresa) }\end{array}$ \\
\hline Dois sigma & 69,15 & 308.537 & - \\
\hline Três sigma & 93,32 & 66.807 & 25 a 40 \\
\hline Quatro sigma & 99,379 & 6.210 & 15 a 25 \\
\hline Cinco sigma & 99,9767 & 233 & 5 a 15 \\
\hline Seis sigma & 99,99966 & 3,4 & $<1$ \\
\hline
\end{tabular}

Fonte: Werkema (2014)

Na metodologia Seis Sigma é comum pelos grupos de trabalho ou equipes envolvidas utilizarem o modelo DMAIC (Definir, Medir, Analisar, Implementar e Controlar) para conduzir a implantação do projeto e permitir uma maior organização durante a execução. Tal ferramenta permite sistematizar em etapas bem definidas a execução do projeto (WERKEMA, 2014).

\subsection{Modelo DMAIC}

Para Santos e Martins (2003) o modelo DMAIC permite a execução de um projeto Seis Sigma de maneira lógica e eficaz, facilitando no gerenciamento dos projetos. A partir das cinco fases que o compõe o projeto é guiado a fim de alcançar os objetivos e metas estabelecidos pelas equipes responsáveis. Cada etapa tem bem definida a sua atividade e faz uso da estratégia breakthrough que significada o particionamento no processo de maneira a possibilitar melhorias.

De acordo com Statamatis (2004), as cinco etapas se constituem por:

Define, que significa definir, refere-se à primeira etapa em um projeto Seis Sigma. Nesta, deve ser definido de maneira clara qual é o problema a ser resolvido ou eliminado do processo, além de ser estabelecidas as equipes e escopo do projeto.

Measure, que em português significa mensurar, trata-se da etapa onde são determinadas as variáveis para análise estatística do problema e na obtenção de informações sobre o processo que podem estar interferindo no problema estudado.

Analyze, cuja tradução é analisar, consiste na etapa onde acontece a análise das informações e dados obtidos na fase anterior. Nesta etapa é possível tirar 
conclusões sobre o as possíveis melhorias e quais prioriza-las. Também, é a etapa onde são identificadas as origens dos problemas e como atuam no processo produtivo.

A etapa seguinte é a Improve, chamada de melhorar, nesta etapa deve ser realizada a implementação das melhorias identificadas e constantemente buscar otimiza-las. Assim, busca-se realizar os ajustes necessários nos processos e implementá-los.

Por fim, a última etapa é a Control (controlar), ou seja, garantir que as melhorias implementadas permaneçam no processo produtivo. Geralmente, buscase monitorar o andamento dos processos a fim de identificar possíveis "fugas" dos parâmetros estabelecidos para o processo.

\subsection{Ferramentas para análise em projetos Seis Sigma}

Na metodologia Seis Sigma é de fundamental importância a utilização das ferramentas adequadas para a identificação, análise e solução dos problemas e proposição de melhorias. Além disso, algumas ferramentas possibilitam a implantação de planos de ação que geram informações necessárias para o controle das variáveis do processo produtivo e permitem verificar se a qualidade está sendo realmente alcançada ou não.

Durante a aplicação do método DMAIC, em cada fase algumas ferramentas são comuns, no entanto, vale ressaltar que não é via de regra a utilização de todas as ferramentas pois cada problema em análise pode precisar de um conjunto diferente de informações e dados.

Há uma enorme gama de ferramentas que podem ser utilizadas para a resolução de problemas, entretanto, para este trabalho são apresentadas a seguir as ferramentas pertinentes para o objeto de estudo de interesse.

\subsubsection{Gráfico de Pareto}

O Princípio de Pareto consiste em uma relação onde $20 \%$ das causas correspondem a $80 \%$ dos problemas (DAYCHOUM, 2008). Conforme Gupta e Sri (2012), o gráfico de Pareto possibilita priorizar as principais causas de problemas por meio de uma ilustração gráfica. Nesta é possível agir sobre a circunstância mais 
propensa a redução de custos ou desperdícios, auxiliando assim a tomada de decisões da empresa.

A Figura 2 apresenta um exemplo de Gráfico de Pareto.

Figura 2 - Gráfico de Pareto

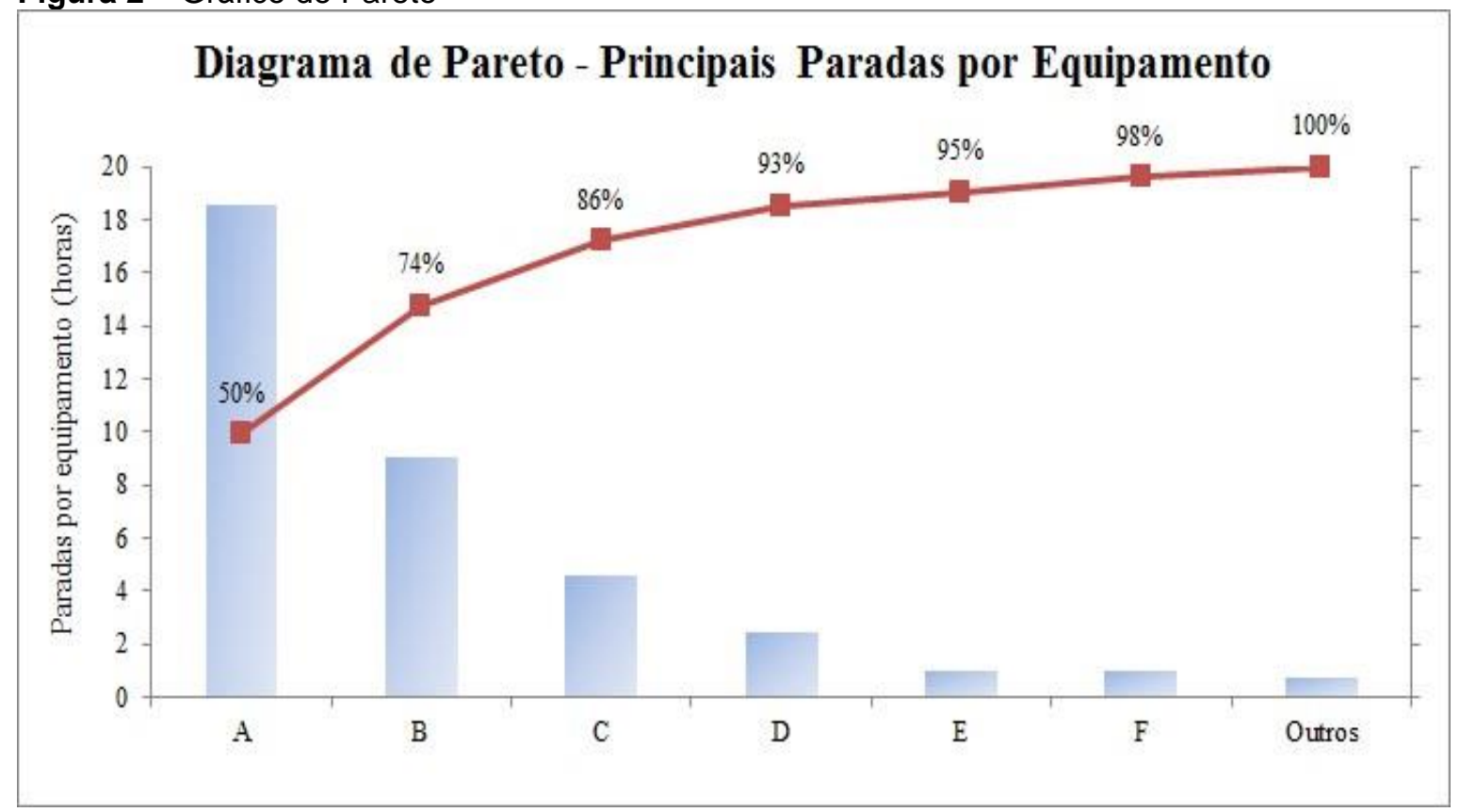

Fonte: Adaptado de Tubaki (2016)

\subsubsection{Diagrama de Causa e Efeito}

Esta ferramenta também pode ser chamada de Ishikawa e mostra visualmente as possíveis causas de um determinado problema. Para tanto, sua estrutura é constituída pelos 6M's, isto é, Mão-de-obra, Método, Meio Ambiente, Matéria-prima, Máquina e Medição, estes permitem separar as causas nestas classificações e facilitar a tomada de decisão na resolução do efeito e na busca por melhorias (MONSANTO, 2012).

Segundo Possarle (2014), essa ferramenta tem como objetivo obter a causa raiz do problema e extrair o máximo de informações pertinentes para o problema em questão. A Figura 3 ilustra um modelo de diagrama de causa e efeito. 
Figura 3 - Exemplo de diagrama de Causa e Efeito

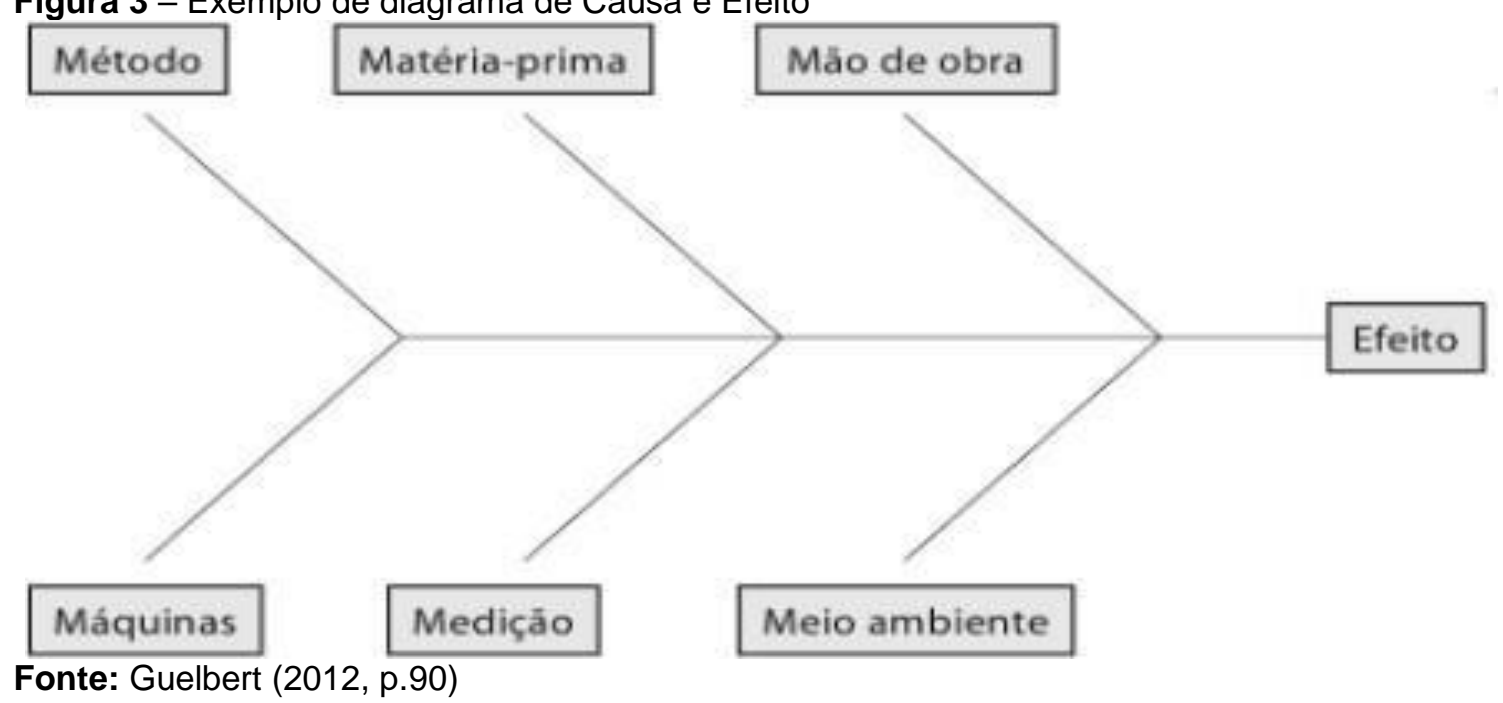

\subsubsection{Brainstorming}

Maximiano (2004) define brainstorming como um conjunto de ideias obtidos a partir de um evento em que os participantes atuam mutuamente, opinando e argumentando a respeito de um determinado tema.

Esta ferramenta é fundamental em projetos de melhoria, pois envolve desde a alta direção até os colaboradores de chão de fábrica, assim todos têm a oportunidade de dar soluções para o problema, além de engajar os funcionários e motivá-los mostrando a importância dos mesmos.

O responsável por conduzir o brainstorming finaliza o evento quando não há mais propostas de soluções ou quando há um número significativo de ideias. Então, estas propostas ou ideias são analisadas e selecionadas para a aplicação (MAXIMIANO, 2004).

\subsubsection{Histograma}

O histograma consiste na distribuição por classes em um gráfico de barras de dados quantitativos, ou seja, é uma forma gráfica de apresentação dos dados em que estão agrupados por classes ou categorias. A sua representação é dada em barras que refletem a frequência de ocorrência dos dados no intervalo definido (classe) (JUNIOR et al., 2006). 
Esta ferramenta funciona como uma fotografia do processo, isto é, ela mostra como está se comportando determinado parâmetro de especificação do produto diante do processo produtivo. A Figura 4 mostra um exemplo de histograma.

Figura 4 - llustração de um Histograma

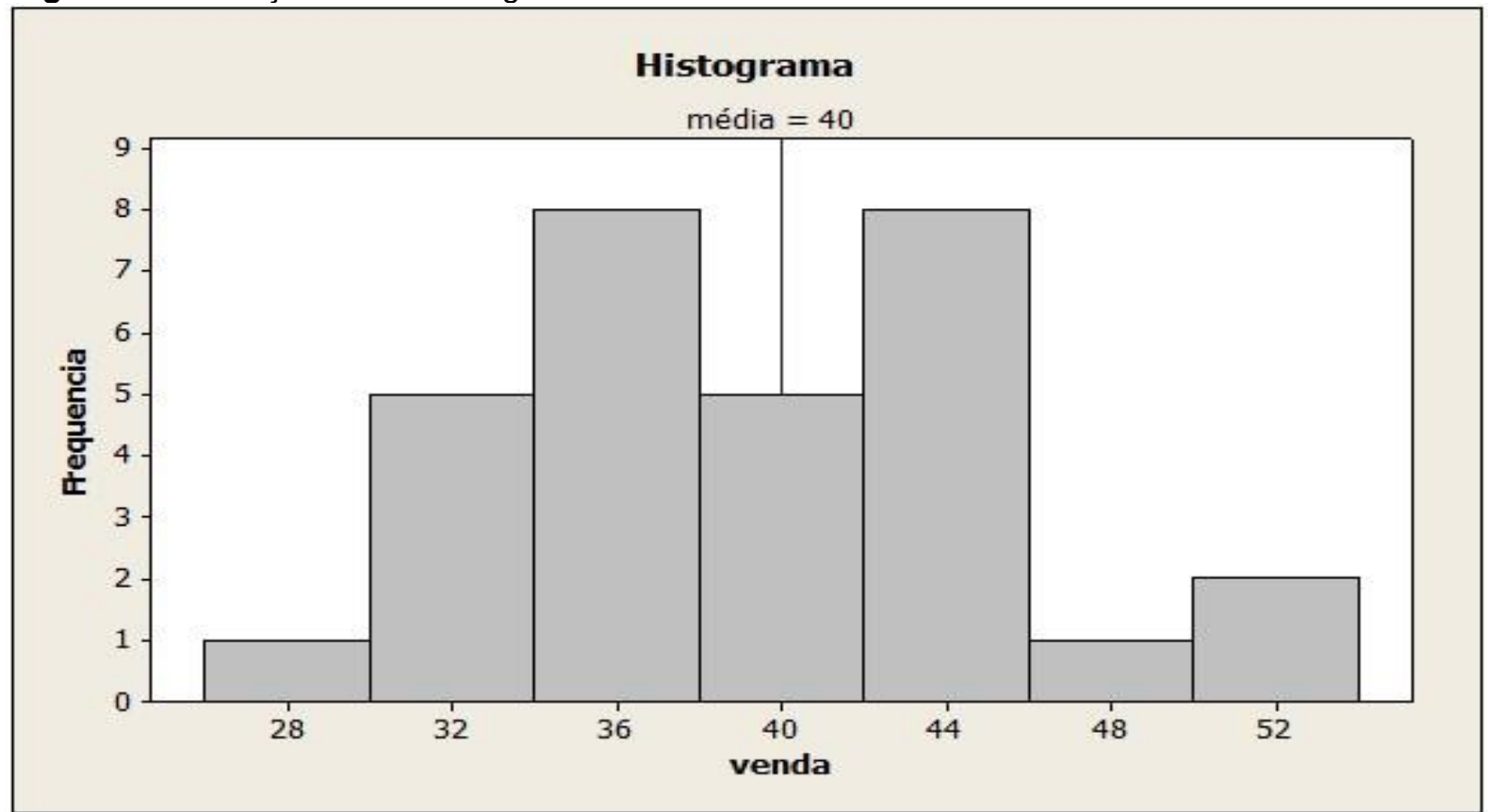

Fonte: Elaborado pelo autor (2019)

\subsubsection{W1H}

Para Werkema (2014, p. 37) após o processo ter sido analisado, deve-se estabelecer um plano de ação composto por um conjunto de medidas a fim de eliminar as causas raízes ou prevenir a ocorrência das mesmas. Assim, esta ferramenta pode auxiliar no estabelecimento destas ações e direcionar a equipe do projeto.

Para a mesma autora a definição da ferramenta é "5W1H: O QUE ("WHAT") será feito, QUANDO (“WHEN") será feito, QUEM (“WHO”) fará, ONDE (“WHERE”) será feito, POR QUE (“WHY”) será feito, COMO (“HOW') será feito”. 
Figura 5 - Ferramenta $5 \mathrm{~W} 1 \mathrm{H}$

\begin{tabular}{|c|c|c|c|c|c|c|c|}
\hline \multirow{2}{*}{0 que } & \multirow{2}{*}{ Como } & \multirow{2}{*}{ Quem } & \multicolumn{2}{|c|}{ Quando } & \multirow{2}{*}{ Onde } & \multirow{2}{*}{ Por que } & \multirow{2}{*}{\begin{tabular}{|c} 
Situaçãa \\
Atual
\end{tabular}} \\
\hline & & & Início & Fim & & & \\
\hline & & & & & & & \\
\hline & & & & & & & \\
\hline & & & & & & & \\
\hline & & & & & & & \\
\hline
\end{tabular}

Fonte: Elaborado pelo autor (2019)

\section{METODOLOGIA}

A metodologia deste trabalho apresenta diversas classificações. No que se refere a natureza da pesquisa, pode ser classificada como aplicada, pois de acordo com Miguel (2010) esse tipo de estudo é caracterizado pela busca de resolução de problemas.

Segundo Oliveira (2012, p.39), as informações baseadas qualitativa e quantitativamente proporcionam uma maior confiabilidade na obtenção dos dados. Desta maneira, enquanto que as informações qualitativas aproximam o pesquisador com a situação em análise, os dados e informações quantitativas possibilitam a mensuração por meios estatísticos e assim, dão apoio ao pesquisador na realização do estudo. Assim, este estudo quanto a abordagem classifica-se como qualiquantitativa.

No que se refere aos objetivos, a pesquisa pode ser classificada como exploratória, pois tem como objetivo obter informações acerca do objeto de estudo de maneira a propiciar maior conhecimento e embasamento sobre o assunto. Tal característica é apresentada por Oliveira (2012, p.65) onde a pesquisa exploratória "desenvolve estudos que dão uma visão geral do fato ou fenômeno estudado".

Quanto aos procedimentos técnicos da pesquisa, pode ser classificada em um estudo de caso. De acordo com Gil (2002) o estudo de caso caracteriza-se por ser um estudo consistente de um ou vários objetos a fim de ter um maior conhecimento sobre estes. Yin (2001) trata do estudo de caso como uma investigação de um determinado fenômeno na vida real, visto que não há uma separação clara entre o fenômeno e o contexto em que se inserem. A Figura 6 ilustra as classificações metodológicas para este trabalho. 
Figura 6 - Classificações da pesquisa

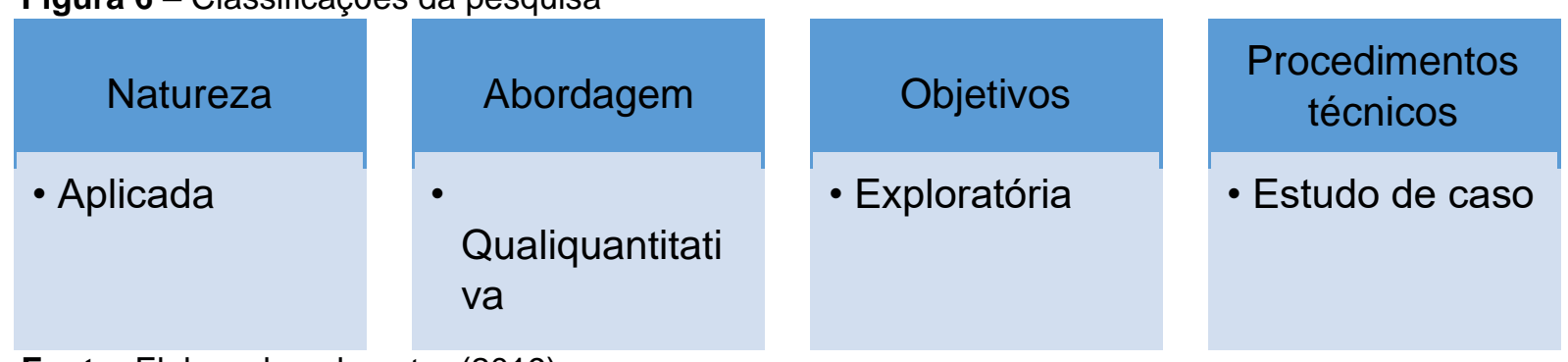

Fonte: Elaborado pelo autor (2019)

Para a realização do estudo de caso, a obtenção de dados e informações foram feitas a partir do acompanhamento da produção e análise do processo produtivo. Além disso, dados históricos da produção foram coletados a fim de ter maior confiabilidade dos dados observados. A Figura 7 mostra esquematicamente 0 método de realização do trabalho.

Figura 7 - Método do trabalho

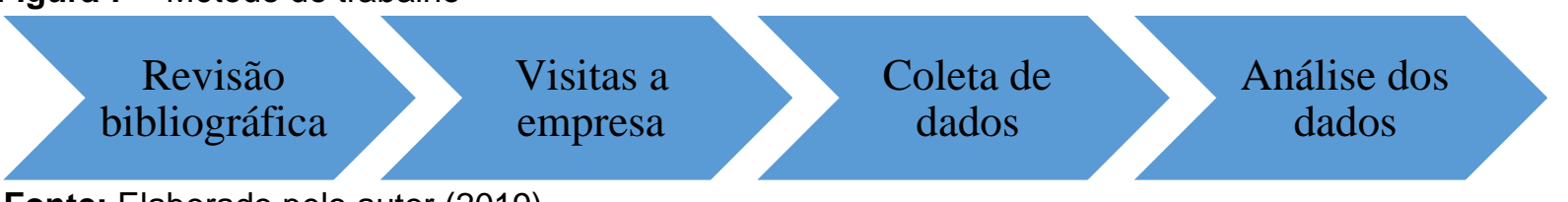

Fonte: Elaborado pelo autor (2019)

A revisão bibliográfica consistiu em buscar na literatura um maior conhecimento sobre o assunto e levantar um embasamento prático-teórico para a realização do estudo. Quanto as visitas a empresa, foram necessárias para se conhecer o setor e posterior início de coleta dos dados. Por fim, a análise dos dados se deu por meio do tratamento de dados e utilização do software Minitab para a obtenção dos resultados quanto a variação do processo.

\section{ESTUDO DE CASO}

O objetivo deste capítulo é realizar o estudo do processo aplicando a modelo DMAIC a fim de implementar a filosofia Seis Sigma no setor em questão. Cada fase do modelo (Definir, Mensurar, Analisar, Melhorar e Controlar) são apresentadas de forma a obter a resolução de problemas e evidenciar como o projeto Seis Sigma pode auxiliar significativamente na redução de custos para a empresa. A aplicação das ferramentas segue de acordo com a obtenção de informações e dados durante o acompanhamento do processo. 


\subsection{A empresa}

A indústria em análise concentra suas ações no setor alimentício, mais precisamente no abate de aves, suínos e bovinos e no processamento destes. A empresa é uma das multinacionais com maior poder sobre o mercado consumidor, estando presente em todos os estados do Brasil e também em países do exterior, tanto em unidades de produção como em produtos comercializados.

Atualmente a unidade em análise empresa aproximadamente 3.000 colaboradores diretamente e realiza operações no abate de suínos e no processamento da carne em diversos produtos como steaks, presunto, mortadela, salame, salsicha, linguiça e pernil.

Este trabalho se concentrou em uma das principais unidades da empresa, que está localizada na região da grande Dourados, interior do estado de Mato Grosso do Sul. O setor escolhido foi o de presunto, visto que é um dos produtos com maior valor agregado pelo processamento da carne suína.

\subsection{Etapas do Modelo DMAIC}

\subsubsection{Define}

O setor de presuntos da empresa é um dos que mais possui valor agregado, ou seja, o processo produtivo do presunto configura aos insumos uma grande quantidade de "valor" ao produto. Tal fato faz com que a atenção da alta diretoria se volte com preocupação para o setor, já que é responsável por cerca de $20 \%$ de todo o faturamento bruto da empresa e contabiliza um custo de aproximadamente $11 \%$ para a mesma. Assim, medidas que envolvam a melhoria da qualidade do produto e também no que se refere ao processo são fundamentais.

A Figura 8 apresenta o fluxograma simplificado do processo de produção. Em seguida é descrito basicamente cada etapa do processo. 
Figura 8 - Fluxograma do processo produtivo do presunto

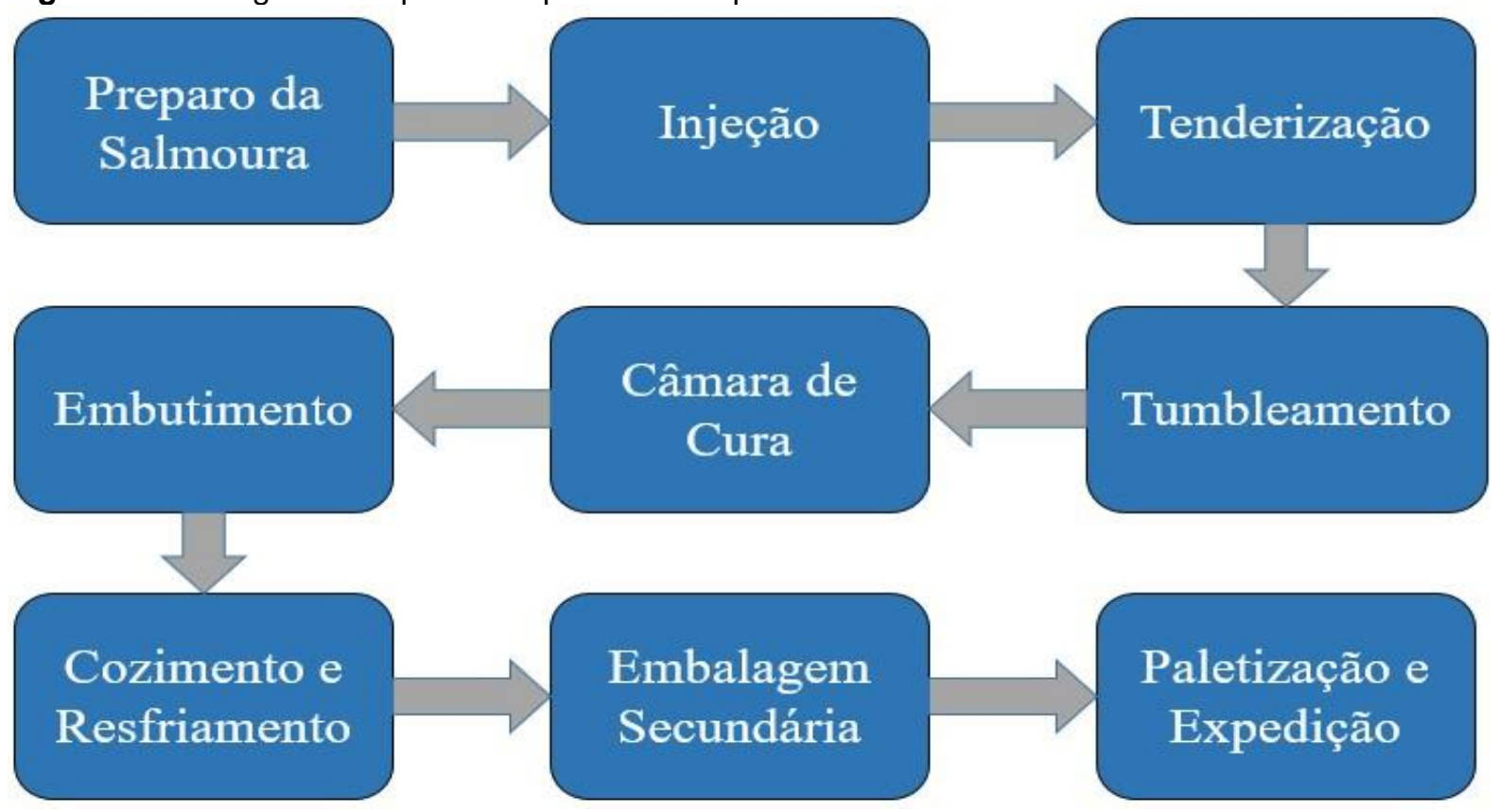

Fonte: Elaborado pelo autor (2019)

Preparo da salmoura: Consiste em uma solução obtida a partir da adição dos ingredientes responsáveis por dar sabor ao presunto. Em seguida essa solução é encaminhada para a injetora.

Injeção: Ocorre a injeção da salmoura dentro da carne utilizada para o presunto (predominantemente o patinho) por meio de uma máquina que atua com agulhas sob pressão.

Tenderização: Fase seguinte da injeção, a carne já injetada de salmoura passa por outro equipamento responsável por realizar pequenos cortes em cada pedaço de carne.

Tumbleamento: Refere-se a etapa onde a carne tenderizada é inserida em uma máquina que realiza o massageamento e quebra da carne por meio de um movimento de rotação, a fim de a carne virar uma massa homogênea.

Câmara de cura: Nesta etapa, a massa obtida pelo processo anterior vai para uma câmara de resfriamento com o objetivo de atingir a temperatura de $5^{\circ} \mathrm{C}$ que é necessária para a próxima etapa.

Embutimento: Por meio de bocais, a massa é injetada dentro da embalagem primária e selada por uma termoformadora e colocada manualmente em formas.

Cozimento e Resfriamento: Na etapa seguinte ao embutimento, as formas são submersas por água em tanques com a temperatura de $90^{\circ} \mathrm{C}$ durante 4 horas. 
Após as 4 horas as formas são retiradas do cozimento e imediatamente colocadas em outro tanque de água com temperatura entre $0^{\circ} \mathrm{C}$ e $10^{\circ} \mathrm{C}$ durante 4 horas para se obter o resfriamento apropriado.

Embalagem Secundária: As formas são retiradas do resfriamento e encaminhadas a um equipamento responsável por desenformar. Após a desenformagem, ocorre a inspeção $100 \%$ de cada presunto por um operador treinado, verificando a presença de bolhas de ar, retenção de líquido ou corpos estrango, e o mesmo direciona o presunto para a esteira que leva o presunto para uma máquina que realiza o encaixotamento do produto.

Paletização e Expedição: Por fim, dois operadores são responsáveis por recolher a caixa da máquina e realizar a paletização em pallets de madeira e leválos com o auxílio de uma transpaleteira até o setor de expedição.

Tomando conhecimento do processo produtivo, cabe ressaltar os principais problemas observados no produto conforme o acompanhamento das atividades industriais. O Quadro 2 apresenta os principais problemas e o número de ocorrência médio mensal de reprocesso.

Quadro 2 - Principais problemas e frequência de ocorrência

\begin{tabular}{|c|c|}
\hline Problema & Frequência Mensal (unidades) \\
\hline Bolha de Ar & 5602 \\
\hline Retenção de líquido & 6310 \\
\hline Corpo estranho & 110 \\
\hline Anomalia de matéria-prima & 4790 \\
\hline Peso abaixo ou acima da especificação & 4880 \\
\hline
\end{tabular}

Fonte: Elaborado pelo autor (2019)

De acordo com os dados do quadro, nota-se que a retenção de líquido apresenta um maior número de ocorrência, porém o custo para reprocessar o presunto sob cada um destes problemas é diferente, pois envolve uma etapa diferente do processo onde o mesmo pode ser reprocessado.

A presença de bolha de ar no presunto consiste em pequenos espaços sem o completo preenchimento de massa, formando bolhas de aproximadamente $1 \mathrm{~cm}$, tornando o produto visualmente indesejável. Já a retenção de líquido refere-se a formação de camadas de água que infiltram no presunto durante o cozimento e resfriamento. O corpo estranho é a presença de qualquer partícula ou objeto na 
massa do presunto, não havendo a possibilidade de reprocessamento do mesmo, sendo que é classificado então como descarte e é destinado a graxaria para eliminação. A anomalia de matéria-prima consiste em pedaços de carne com coloração escurecida ou esbranquiçada provenientes das condições de temperatura em que a carne foi submetida. Por fim, o peso fora da especificação refere-se ao presunto em que foi embalado com o peso fora do intervalo de $3,3 \mathrm{Kg} \mathrm{e} 3,6 \mathrm{Kg}$, que é o padrão adotado pela empresa.

Em estudos anteriores realizados pela empresa, tem-se os custos unitários de reprocesso para cada tipo de problema. O quadro 3 ilustra os resultados obtidos.

Quadro 3 - Custo unitário de reprocesso por problema

\begin{tabular}{|c|c|}
\hline Problema & Custo unitário (RS) \\
\hline Bolha de Ar & 1,66 \\
\hline Retenção de líquido & 1,43 \\
\hline Corpo estranho & 5,8 \\
\hline Anomalia de matéria-prima & 2,75 \\
\hline Peso abaixo ou acima da especificação & 3,97 \\
\hline
\end{tabular}

Fonte: Elaborado pelo autor (2019)

Desta maneira, para uma melhor definição do problema a ser atacado podese fazer uso de um Gráfico de Pareto, visto que apesar de o problema de retenção de líquido ter uma maior frequência de ocorrência, mas o custo de reprocesso do mesmo é o menor dentre os cinco observados. A Figura 9 mostra o gráfico obtido a partir da relação entre o custo e a frequência dos problemas.

A partir do gráfico é possível ver que o problema que apresenta maior impacto nos custos é o peso abaixo ou acima da especificação, apresentando quase $40 \%$ no custo de reprocesso, enquanto que a anomalia de matéria-prima representa aproximadamente $25 \%$ do custo. Desta maneira, o foco deste trabalho se concentra na resolução deste problema.

A equipe do projeto para a realização da implantação do projeto Seis Sigma conta com a colaboração do Supervisor de Produção, Inspetor da Qualidade, Operadores de Produção e Controlador de Produção. 
Figura 9 - Gráfico de Pareto para os problemas

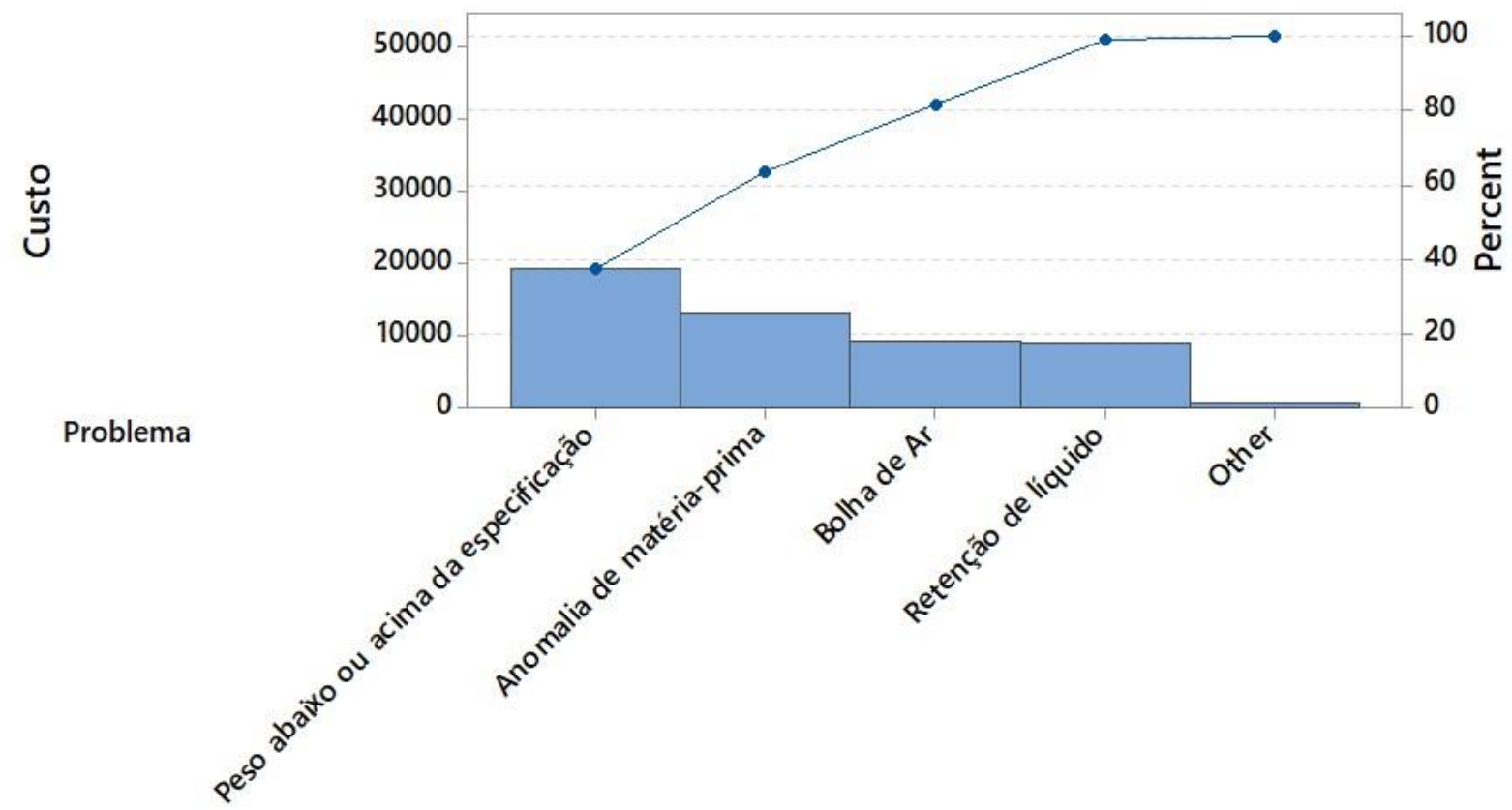

Fonte: Elaborado pelo autor (2019)

\subsubsection{Measure}

Após a definição do problema a ser tratado, a segunda etapa do modelo DMAIC consiste em verificar o sistema de medição e estabelecer estatisticamente o sistema de medição para a obtenção de dados confiáveis para a posterior análise.

Um plano de coleta de dados pode ser definido em torno do problema, visando a obtenção de informações que possam evidenciar a atual situação do sistema e facilitar a identificação das causas do problema.

A partir do problema definido na etapa anterior, um plano de amostragem pode ser definido pela equipe do projeto. A cada 30 minutos, uma peça de cada bocal deve ser retirada e aferida a massa da mesma, obtendo um total de 14 amostragens durante o turno e um total de 56 peças retiradas, já que em cada amostragem são retiradas 4 peças, com base na disponibilidade de 420 minutos no turno.

A Figura 10 a seguir refere-se ao histograma obtido a partir da aferição da massa de cada peça retirada na amostragem. 
Figura 10 - Histograma do processo de embutimento

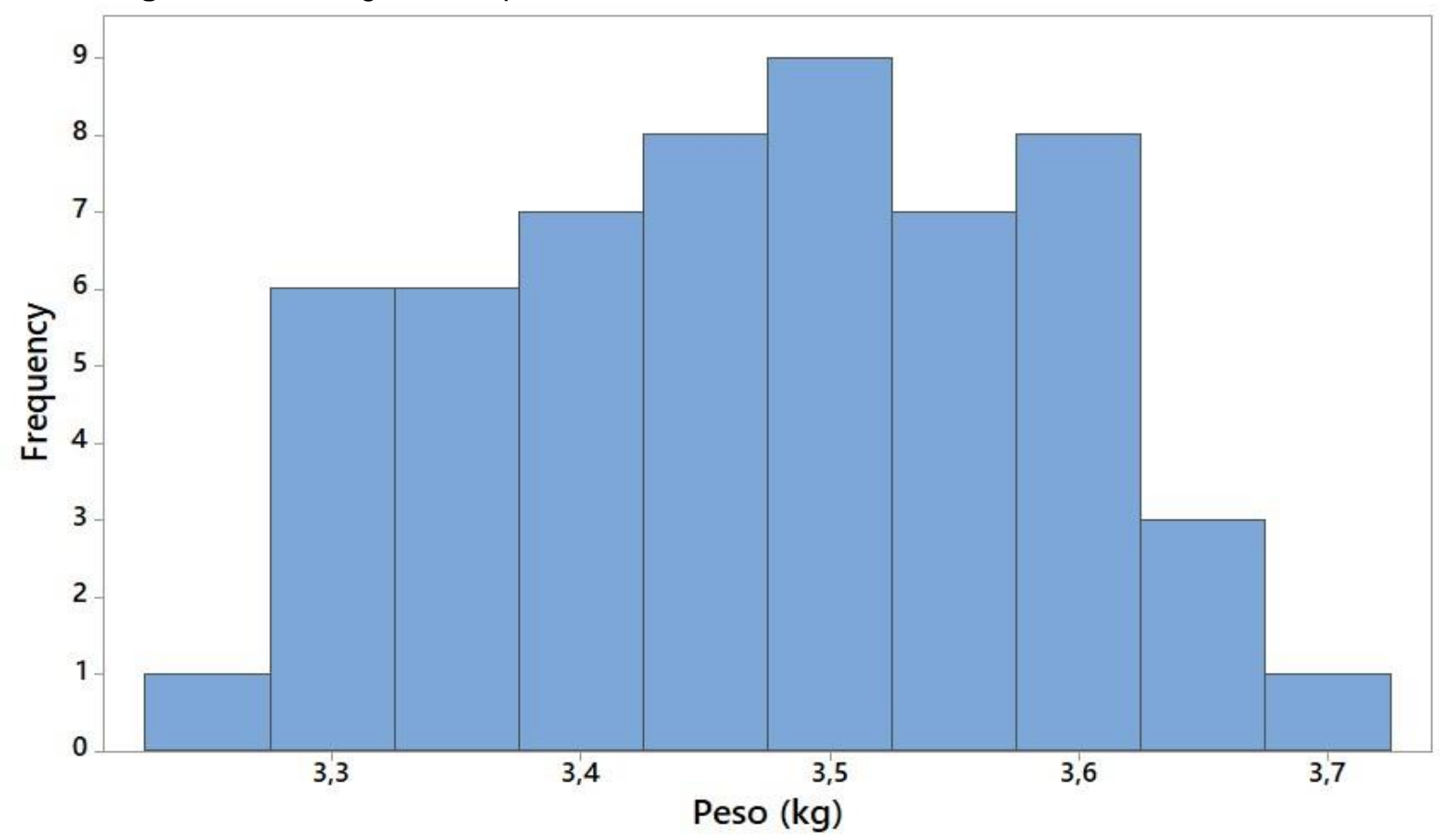

Fonte: Elaborado pelo autor (2019)

Cabe ressaltar que os limites de especificação, LIE (Limite Inferior de Especificação) e LSE (Limite Superior de Especificação) são $3,3 \mathrm{Kg}$ e $3,6 \mathrm{Kg}$ respectivamente. Os mesmos foram estabelecidos pela alta direção em conjunto com o setor da garantia da qualidade ainda na fase de estudos do produto para comercialização no mercado consumidor.

Para avaliar a capacidade preliminar do processo é preciso primeiramente realizar o teste de normalidade para os dados coletados na amostragem. Com o auxílio do software Minitab é possível realizar tal análise e, conforme mostra a Figura 11 o resultado obtido do Pvalue é 0,052 ou seja, é maior que 0,05 e, portanto, possui uma distribuição Normal.

O nível sigma preliminar do processo pode ser determinado com os dados validados pelo teste de normalidade. A Figura 12 mostra o resultado do nível sigma obtido a partir do software. O nível sigma é representado pelo valor dado pelo $Z$. Bench, onde o mesmo obtido foi de 1,16, ou seja, o nível sigma de qualidade do processo é de $\sigma=1,16$, representando um valor extremamente baixo de acordo com a escala de nível de qualidade que varia de 1 a 6 conforme (WERKEMA, 2014). Destaca-se que os limites de especificação LSL e USL, equivalem ao LIE e LSE, respectivamente. 


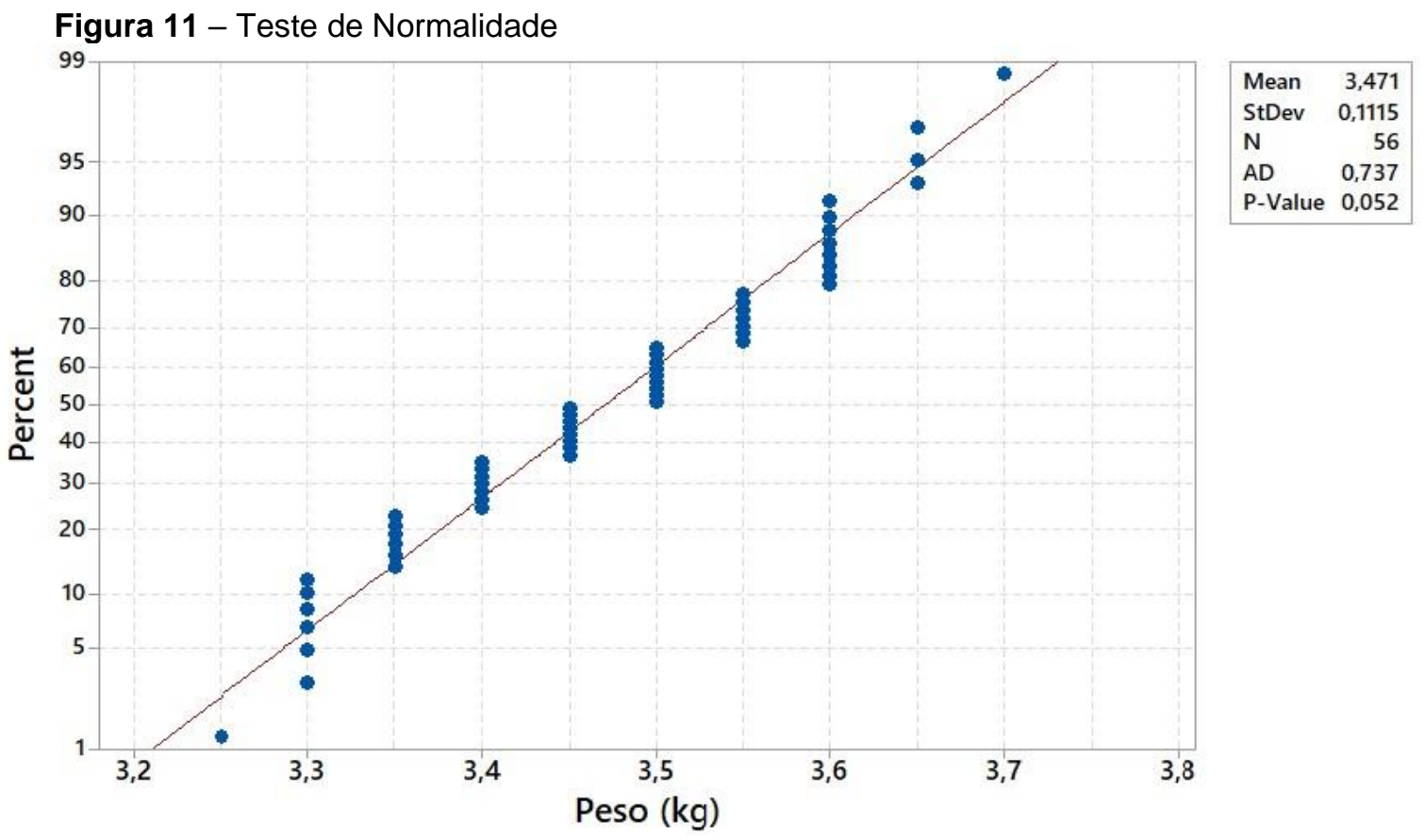

Fonte: Elaborado pelo autor (2019)

Figura 12 - Nível sigma do processo
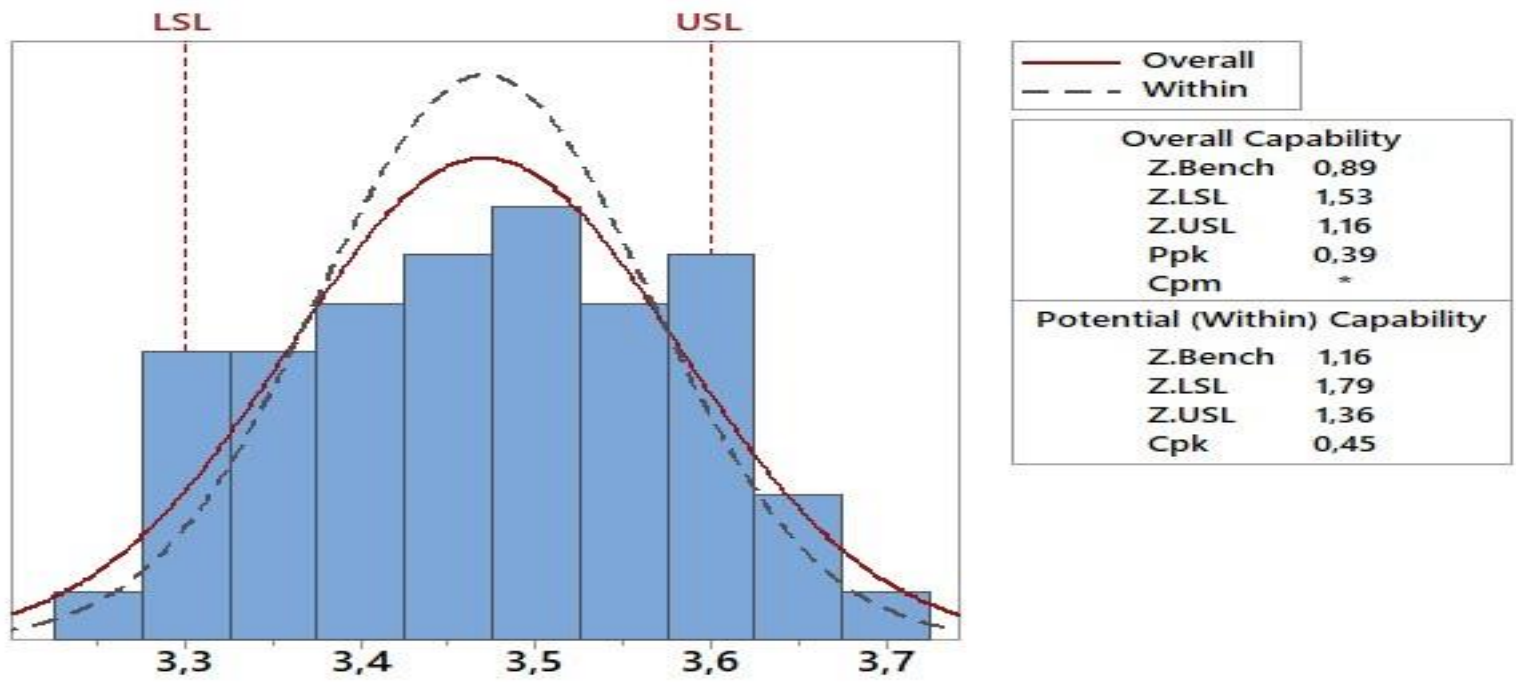

Fonte: Elaborado pelo autor (2019)

Uma segunda análise pode ser feita acerca dos índices de performance Ppk e Cpk obtidos a partir da amostragem com 0,39 e 0,45, respectivamente. Esses valores indicam que o processo está centralizado em torno da média e que o processo está estável e previsível, porém é possível observar que o processo entrega muitos produtos fora da especificação (Cpk e Ppk menores que 1). 


\subsubsection{Analyze}

Uma vez entendida a variação do processo em torno dos limites de especificação e determinado o nível sigma as ações devem ser focadas em encontrar a causa raiz que influencia a termoformadora a inserir a quantidade inadequada de massa dentro das formas.

A realização de um brainstorming permitiu que todos os envolvidos pudessem dar ideias e indicativos das possíveis causas do problema. Logo, foi possível a elaboração de um diagrama de causa e efeito para o problema em questão.

A Figura 13 ilustra o diagrama elaborado com as ideias expostas.

Figura 13 - Diagrama de Causa e Efeito

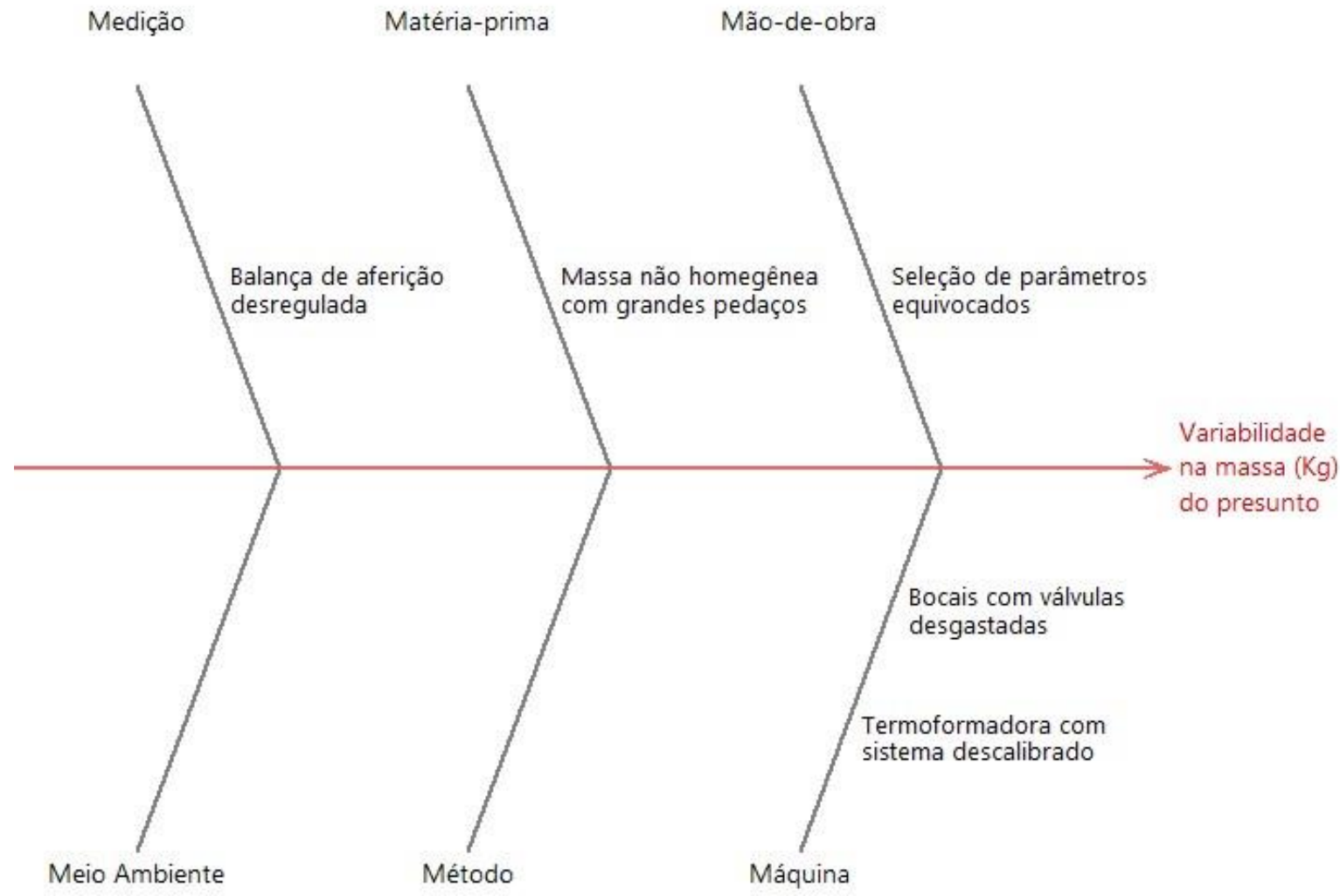

Fonte: Elaborado pelo autor (2019)

Com a realização do diagrama destaca-se cinco possíveis causas para o efeito da variabilidade da massa $(\mathrm{Kg})$ do produto. Estas estão atreladas a quatro diferentes M's. Quanto a Medição, a causa proposta é de que a balança de aferição esteja desregulada, trata-se de um erro operacional, pois este equipamento deveria ser constantemente calibrado conforme o plano de manutenção periódica de instrumentos de aferição. 
Já quanto a Matéria-prima, a causa apontada foi de que a massa do presunto não está homogênea suficientemente e apresenta grandes pedaços de carne que não foi tenderizada adequadamente, isso faz com que parte da massa do presunto que daria o peso ideal fique presa nos bocais ou a quantidade inserida ultrapasse $o$ peso especificado.

Com relação a Mão-de-obra, a seleção de parâmetros equivocados foi citada como possível causa. Quatro operadores de produção são responsáveis pela termoformadora, embora todos sejam treinados no padrão técnico do processo, existe a possibilidade de ao selecionar o programa de operação da máquina colocarem os parâmetros de pressão, peso e temperatura errados e, portanto, alterar significativamente as condições operacionais da termoformadora.

Por fim, duas possíveis causas foram propostas no que tange a Máquina, a primeira se refere com a termoformadora estar com o sistema descalibrado, ou seja, a máquina não opera com a confiabilidade adequada em que foi estabelecido os parâmetros de operação definidos pelo fabricante para a mesma, isto pode ser decorrente de quedas de energia e/ou ausência de limpeza e lubrificação interna dos componentes móveis. A segunda causa trata-se do desgaste das válvulas dos bocais, isso porque cada bocal possui uma vedação que auxilia no processo de cessar a quantidade de massa de presunto a ser inserida.

A fim de priorizar as causas a serem tratadas primeiro, foi realizado uma votação por cada um dos envolvidos no projeto Seis Sigma e pelos quatro operadores responsáveis pela termoformadora. A Figura 14 apresenta os resultados obtidos com a votação.

Figura 14 - Carta de multivotação para as causas da variabilidade

\begin{tabular}{|c|c|c|c|c|c|c|c|c|c|}
\hline \multicolumn{2}{|r|}{ MULTIVOTAÇÃO } & \multirow{2}{*}{ 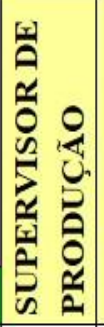 } & \multirow{2}{*}{ 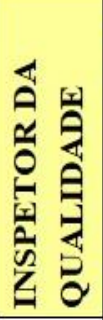 } & \multirow{2}{*}{ 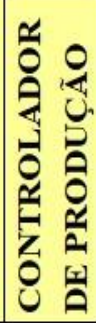 } & \multirow{2}{*}{ 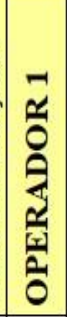 } & \multirow{2}{*}{ 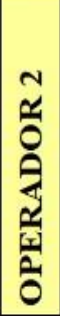 } & \multirow{2}{*}{ 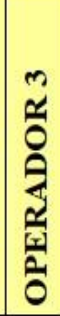 } & \multirow{2}{*}{ 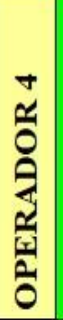 } & \multirow{2}{*}{ E } \\
\hline & CAUSAS POTENCIAIS & & & & & & & & \\
\hline 1 & Massa não homogênea com grandes pedaços & & 1 & & & 1 & & & 2 \\
\hline 2 & Balança de aferição desregulada & & & & & & & & 0 \\
\hline 3 & Seleção de parâmetros equivocados & & & & 1 & & 1 & & 2 \\
\hline 4 & Termoformadora com sistema descalibrado & 1 & 1 & 1 & & 1 & 1 & 1 & 6 \\
\hline 5 & Bocais com válvulas desgastadas & 1 & & 1 & 1 & & & 1 & 4 \\
\hline
\end{tabular}

Fonte: Elaborado pelo autor (2019) 
Cada participante pode votar em duas causas as quais o mesmo considerasse o principal motivo para o efeito. Assim, para cada escolha o número 1 era atribuído e no final realizada a soma total para cada efeito. A partir deste resultado, ambas as duas causas advindas da máquina foram as mais votadas e, portanto, escolhidas para serem tratadas inicialmente.

Por se tratar de características elétrico-mecânicas a equipe do projeto por meio de uma reunião, entrou em consenso sobre a necessidade de se realizar uma manutenção técnica emergencial do equipamento e também estabelecer um plano de manutenção que possibilitasse a sustentação das melhorias a serem realizadas e a prevenção do reaparecimento das causas.

\subsubsection{Improve}

Duas ações de melhoria foram desenvolvidas pela equipe para o tratamento da anomalia: a realização de uma manutenção emergencial da termoformadora e a elaboração de um plano de manutenção preventiva. Para tanto, o setor da manutenção passou a fazer parte da equipe do projeto com a inclusão de dois engenheiros mecânico.

\subsubsection{Manutenção Emergencial}

A Figura 15 ilustra o plano de ação simplificado desenvolvido, para isso utilizou-se a ferramenta $5 \mathrm{~W} 1 \mathrm{H}$.

Figura 15 - Plano de ação 5W1H

\begin{tabular}{|c|c|c|c|c|c|c|}
\hline 0 que & Como & Quem & Quando & Onde & Por que & $\begin{array}{c}\text { Situação } \\
\text { Atual }\end{array}$ \\
\hline Limpeza interna & $\begin{array}{c}\text { Desmontagem e higienização a } \\
\text { seco das peças }\end{array}$ & $\begin{array}{c}\text { Setor } \\
\text { Manutenção }\end{array}$ & Imediato & Setor Presunto & $\begin{array}{c}\text { Retirada de partículas } \\
\text { em excesso }\end{array}$ & Concluido \\
\hline Lubrificação dos componentes & $\begin{array}{c}\text { Engraxar os componetes com } \\
\text { óleo especifico }\end{array}$ & $\begin{array}{c}\text { Setor } \\
\text { Manutenção }\end{array}$ & Imediato & Setor Presunto & $\begin{array}{c}\text { Reduzir friç̧ão entre } \\
\text { peças }\end{array}$ & Concluido \\
\hline Troca de váltula dos bocais & Substituição das válvulas antigas & $\begin{array}{c}\text { Setor } \\
\text { Manutenção }\end{array}$ & Imediato & Setor Presunto & $\begin{array}{c}\text { Remover peças com } \\
\text { fadiga permanente }\end{array}$ & Conchuido \\
\hline Verificar ocorrência de oscilações & $\begin{array}{c}\text { Instalação de voltimetro na } \\
\text { energização da máquina }\end{array}$ & $\begin{array}{c}\text { Setor } \\
\text { Manutenção }\end{array}$ & Imediato & Setor Presunto & $\begin{array}{c}\text { Oscilações de potência } \\
\text { podem descalibrar o } \\
\text { sistema }\end{array}$ & Conchuido \\
\hline
\end{tabular}

Fonte: Elaborado pelo autor (2019) 
Conforme a ilustração, quatro ações emergências foram estabelecidas de maneira a tratar as duas causas que foram identificadas para a ocorrência do efeito da variabilidade do peso do presunto. Cada uma destas medidas tem pequeno impacto no que se refere a custo para a organização, logo, não foram consideradas para fins de representação.

Todas as ações foram imediatamente aprovadas pela alta direção e implementadas no setor em regime de urgência.

\subsubsection{Checklist Diário}

A segunda ação tomada foi a elaboração de um simples checklist para que o processo somente seja iniciado sob condições ideais de operação, além disso, o mesmo deveria ser aplicado novamente após quatro horas de funcionamento do turno, pois é o momento em que se retoma as operações após os colaboradores terem o horário de janta e, por fim, ao final do turno de maneira que a termoformadora tenha encerrado o turno com o funcionamento normal. O quadro 4 mostra o checklist elaborado.

Quadro 4 - Checklist para a termoformadora

\begin{tabular}{|c|c|c|}
\hline \multicolumn{2}{|c|}{ Checklist Diário } \\
\hline Característica & Padrão & Observado \\
\hline Inspeção Visual & Limpeza e organização & \\
\hline Água & Corrente & \\
\hline Pressão & 5,5 Bar & \\
\hline Limites de especificação & 3,3 a 3,6 $(\mathrm{Kg})$ & \\
\hline Temperatura da massa & Abaixo de $6^{\circ} \mathrm{C}$ & \\
\hline Voltagem & Sem oscilações & \\
\hline
\end{tabular}

Fonte: Elaborado pelo autor (2019)

Todos os parâmetros possuem o padrão de operação e em caso de divergência, qualquer um dos quatro operadores da máquina pode fazer a observação da anomalia no checklist e assim, chamar a equipe do projeto para corrigir antes que o processo seja iniciado. 


\subsubsection{Control}

Para garantir que as medidas tomadas garantam a eliminação do efeito da variabilidade, foi definido a utilização constante do plano de amostragem definido na etapa Measure e a análise dos dados obtidos elaborando um novo histograma e calculando o nível sigma de qualidade. Como a busca pela qualidade é continua, o projeto Seis Sigma entra em um ciclo de melhoria.

A medida em que são identificadas novas possíveis causas, o modelo DMAIC mais uma vez é acionado, transpassando por todas as etapas aqui citadas a fim de se obter continuamente uma maior confiabilidade no produto fabricado.

\section{RESULTADOS E DISCUSSÕES}

Visando melhorar o processo produtivo como um todo, o projeto Seis Sigma foi sugerido para ser implantado abrangendo todo o setor, evidenciando novas anomalias e causas raízes a serem tratadas. Para isso, a mudança cultural é necessária e, desta maneira, foi proposto a inclusão de todos os colaboradores do setor para a realização de treinamentos no sistema de garantia da qualidade, assim como, a participação efetiva dos mesmos na resolução dos problemas a serem identificados.

O desenvolvimento pessoal é primordial para o sucesso do projeto e das ações a serem executadas. Assim, através de capacitações os colaboradores estão cada vez mais aptos tecnicamente na identificação e solução de problemas na linha de produção.

Com a implementação das ações citadas nas etapas do DMAIC, alguns resultados preliminares puderam ser observados. A Figura 16 mostra o novo histograma para a termoformadora.

Conforme ilustra o novo histograma, o processo está sob controle e não houve nenhum presunto que apresentasse peso maior ou menor do que a especificação. O teste de normalidade retornou um valor de Pvalue de 0,959, ou seja, os dados se comportam com uma distribuição Normal. 
Figura 16 - Histograma após a manutenção emergencial

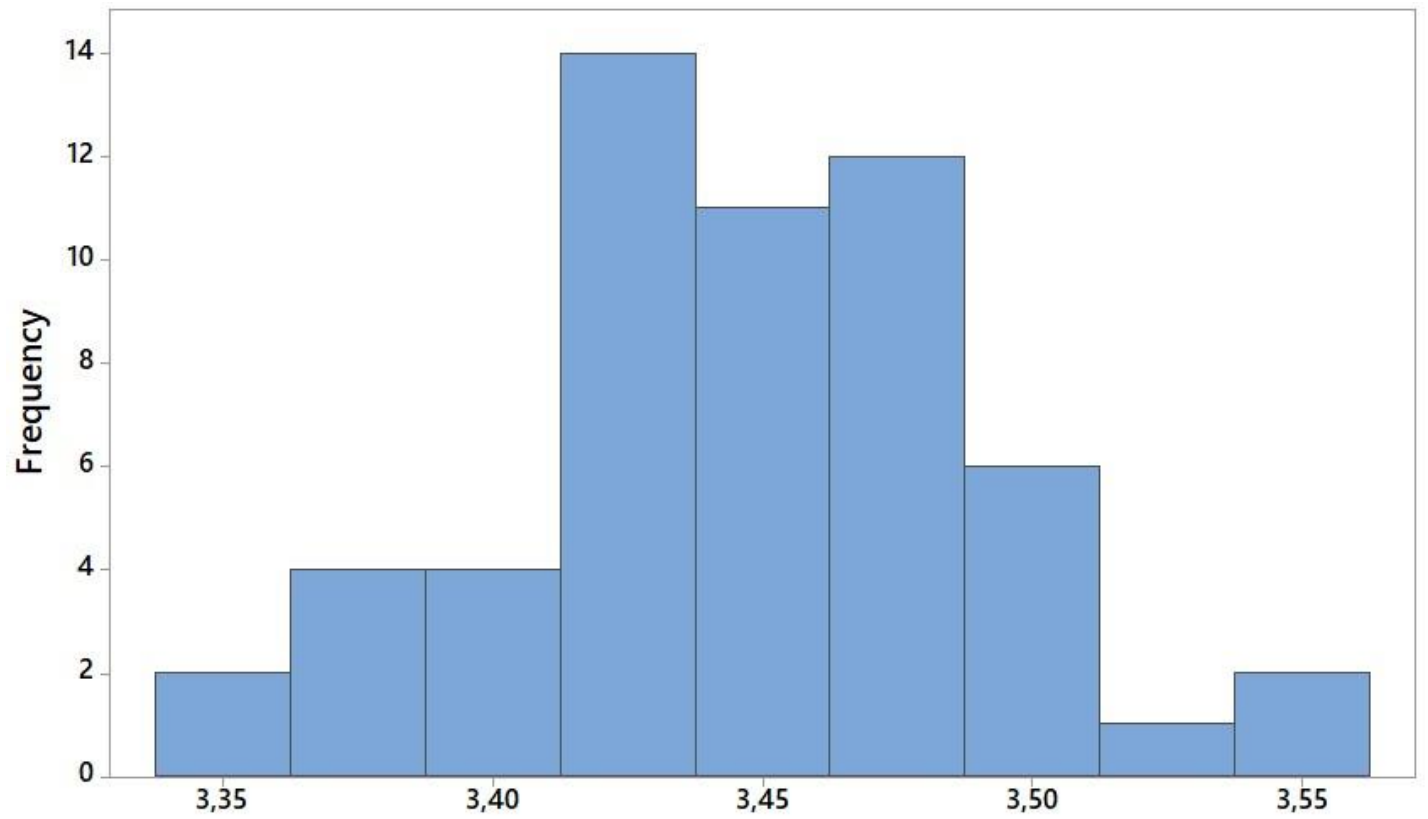

Fonte: Elaborado pelo autor (2019)

Desta maneira foi possível verificar o novo nível sigma a partir destas melhorias implementadas. A Figura 17 mostra que a variação do peso do presunto foi entre $3,35 \mathrm{Kg}$ e $3,55 \mathrm{Kg}$ e, portanto, possui uma folga de 0,5 $\mathrm{Kg}$ em ambos os limites.

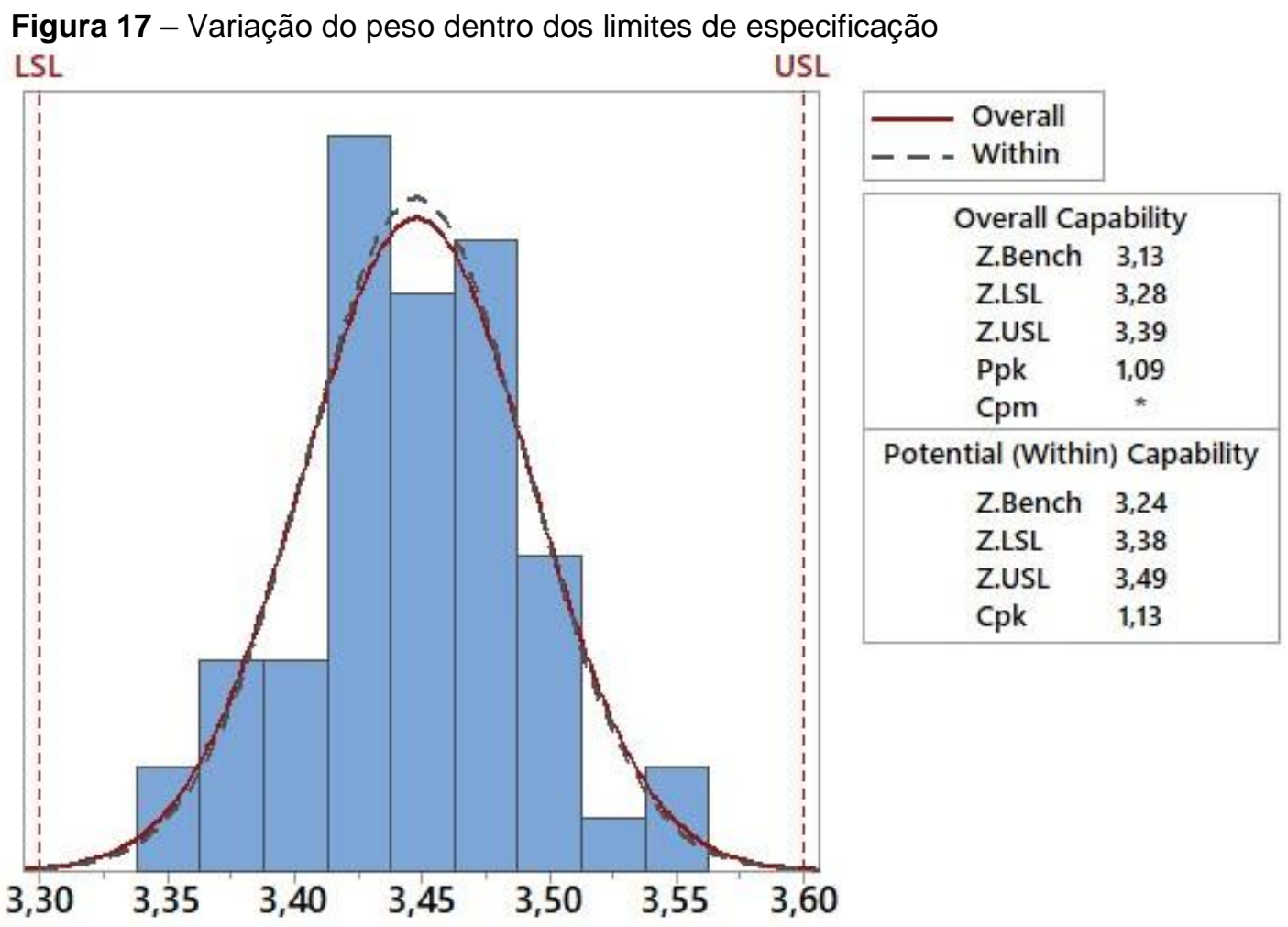

Fonte: Elaborado pelo autor (2019)

Revista Produção Online. Florianópolis, SC, v. 20, n. 2, p. 546-574, 2020 
Essa folga de $0,5 \mathrm{k}$ pode ser representada em termos dos índices de performance Ppk e Cpk que agora passam a ser de 1,09 e 1,13, respectivamente. Tal resultado para ambos acima de 1 , significa que o processo atende às especificações e ainda possui uma pequena folga em relação aos limites e, portanto, não há produção de presunto fora das especificações.

O nível sigma obtido foi de 3,24, representando um ganho significativo no processo. Tal pode ser citado como uma redução de custos com reprocesso e como a melhoria na eficiência produtiva devido a não perca de tempo para reprocessar o produto fora da especificação. Diante disso, pode-se aproximar uma redução de custo de $\mathrm{R} \$ 19.373,60$ mensal, obtido a partir da multiplicação da média mensal de reprocesso com o peso fora da especificação pelo preço unitário de reprocesso.

Destaca-se também a criação de um plano de manutenção preventiva para o equipamento, a fim de garantir a confiabilidade e que as melhorias sejam sustentadas a longo prazo. O Quadro 6 mostra o esquema básico criado para o gerenciamento de tempo da manutenção.

Quadro 5 - Plano de manutenção para a termoformadora

\begin{tabular}{|c|c|c|c|c|c|}
\hline \multirow{2}{*}{ Ação } & \multicolumn{5}{|c|}{ Periodicidade } \\
\cline { 2 - 6 } & Diária & Mensal & Trimestral & Semestral & Anual \\
\hline Checklist & $\mathrm{X}$ & & & & \\
\hline Lubrificação & & & $\mathrm{X}$ & & \\
\hline Calibração & & $\mathrm{X}$ & & & \\
\hline Limpeza interna & & & & $X$ & \\
\hline Troca de válvulas & & & & & $X$ \\
\hline Inspeção geral & & & & & $X$ \\
\hline
\end{tabular}

Fonte: Elaborado pelo autor (2019)

O plano de manutenção preventiva apesar de básico, pode significativamente auxiliar a equipe do setor de manutenção a estabelecer um cronograma para a realização das manutenções, evitando que haja novamente os problemas citados com a termoformadora, além de outras paradas não citadas. 


\section{CONCLUSÃO}

A busca incessante por melhorias de qualidade no produto e no processo e a redução de custos e desperdícios se fazem necessários a partir da premissa da crescente competitividade no ambiente empresarial.

Com esta abordagem, este trabalho visou não só a implementação da metodologia Seis Sigma como um projeto único, mas também como uma filosofia a ser seguida na busca pela qualidade, eliminação de desperdícios e redução de custos. Para tanto, o modelo DMAIC foi utilizado a fim de auxiliar na coordenação das etapas e de uma maneira racional aplicar as ferramentas da qualidade na resolução do problema.

A realização do estudo de caso permitiu identificar e priorizar o problema que mais causava custos para o setor no que se refere ao reprocesso e, por meio do projeto Seis Sigma entender melhor as causas do problema e estabelecer medidas apropriadas para o tratamento da anomalia.

Desta maneira, evidenciou-se que o problema do peso do presunto fora dos limites de especificação e, portanto, teriam que ser reprocessados poderia ser resolvido a partir de uma manutenção dos bocais da termoformadora. Além disso, cabe ressaltar a proposta de uma manutenção preventiva para que as ações tomadas sejam sustentadas a longo prazo.

Outro ponto a se destacar é o comprometimento de todos os envolvidos no projeto, visto que é primordial a participação efetiva desde a alta direção até os operadores de chão de fábrica. Assim, mais do que uma metodologia, a aplicação da mesma propõe uma mudança na cultura organizacional para com a qualidade, mostrando que é possível com a colaboração de todos obter ganhos significativos a curto, médio e longo prazo.

A principal relevância para o sucesso do projeto consiste na mudança de cultura para com os colaboradores que estão todos os dias nas funções e veem os problemas constantemente. Logo, promover o desenvolvimento dos mesmos é de suma importância para que auxiliem em projetos futuros, dado que o projeto pode servir como base para projetos futuros em outros problemas, principalmente por no início do projeto, outros problemas terem sido destacados também e assim estes 
podem ser tratados a partir da aplicação do modelo DMAIC novamente, funcionando em um ciclo de melhoria continua.

Com essa perspectiva, trabalhos futuros podem ser realizados a fim de possibilitar o estudo das variáveis e causas que interferem no surgimento destes problemas, bem como, propiciar mecanismos para a solução dos mesmos. Ademais, o projeto de aplicação da metodologia Seis Sigma se restringiu a apenas um dos problemas identificados, devido ao curto espaço de tempo disponível para a obtenção de dados e informações do setor, além da baixa disponibilidade dos operadores e supervisor no envolvimento do projeto, limitando a obtenção de informações qualitativas através de conversas informais. Sendo assim, reforça-se a ideia de projetos futuros.

\section{REFERÊNCIAS}

BETTS, Alan; et al. Gerenciamento de operações e de processos princípios e práticas de impacto estratégico. 2. ed. Porto Alegre: Bookman, 2013.

CARPINETTI, L. C. Gestão da qualidade: conceitos e técnicas. 2. ed. São Paulo: Atlas,2012.

DAYCHOUM, Merhi. $\mathbf{4 0}+\mathbf{2}$ ferramentas e técnicas de gerenciamento. 2. ed. Rio de Janeiro: Brasport, 2008.

ECKES, G. The Six Sigma Revolution. 4. Ed. Rio de Janeiro: Elsevier, 2001.

GIL, A. C. Como elaborar projetos de pesquisa. 4. ed. São Paulo: Atlas, 2002.

GUELBERT, Marcelo. Estratégia de gestão de processos e da qualidade. Curitiba: lesde Brasil, 2012.

GUPTA, Praven; SRI, Arvin. Seis sigma: virtualmente sem estatística. 1. ed. Canadá: Vida Econômica Editorial, 2012.

HARRY, M. J.; SCHROEDER, R. Six Sigma: a breackthrough strategy for profitability. New York: Quality Progress, 1998.

JUNIOR, I. M. et al. Gestão da qualidade. 8. ed. Rio de Janeiro: Editora FGV, 2006. 196 p.

KLEFSJO, B., WIKLUND, H., EDGEMAN, R.L. Six Sigma seen as a methodology for total quality management. Measuring Business Excellence 5, p. 31-35, jan. 2001. https://doi.org/10.1108/13683040110385809

MANAGEMENT, HSM. Seis Sigma: memórias do pioneiro". 2006. Disponível em www.minitabbrasil.com.br. Acesso em: 16 jan. 2019. 
MAXIMIANO, Antonio Cesar Amaru. Introdução à administração. 6. ed. São Paulo: Atlas, 2004.

MIGUEL, P. A. C. Metodologia de pesquisa em engenharia de produção e gestão de operações. Rio de Janeiro: Elsevier, 2010.

MONSANTO, Six Sigma: treinamento Six Sigma para Green Belts. São Paulo, Pompéia, 2012.

NICOLETTI JÚNIOR, Alaércio. Introdução ao lean seis sigma. Brasil: Clube dos Autores, 2007.

OLIVEIRA, Maria Marly de. Como fazer pesquisa qualitativa. Petrópolis: Vozes, 2012.

POSSARLE, Roberto. Ferramentas da qualidade. São Paulo: Senai-SP Editora, 2014. $256 p$

REBELATO, Marcelo Giroto; RODRIGUES, Andréia Marize; RODRIGUES, Isabel Cristina. Análise das lacunas presentes na integração da manufatura enxuta com a metodologia Seis Sigma. In: ENEGEP, 2009. [Anais...]. Salvador, 2009. Disponível em:http://www.abepro.org.br/biblioteca/enegep2009 TN STP 091615 13448.pdf. Acesso em: 28 jan. 2019.

ROTONDARO, R. G. Seis Sigma: estratégia gerencial para a melhoria de processos, produtos e serviços. São Paulo: Atlas, 2008.

SANTOS, B. Adriana; MARTINS F. Manoel. A implementação dos projetos seis sigma contribuindo para o direcionamento estratégico e para o aprimoramento do sistema de medição de desempenho. Revista Pesquisa e Desenvolvimento Engenharia de Produção, n.1, p. 1-14, 2003.

SLACK, N. et al. Administração da produção. 3. ed. São Paulo: Atlas, 2009.

STAMATIS, H. DEAN. Six sigma fundamentals: a complete guide to the system, methods and tools. New York: Productivity Press, 2004.

TUBAKI, Ana Paula. Aplicação de ferramentas utilizando a metodologia seis sigma para redução de perdas em uma indústria do segmento alimentício. 2016.

WERKEMA, C. Ferramentas estatísticas básicas do lean seis sigma integrada ao PDCA e DMAIC.1 ed. Rio de Janeiro: Elsevier, 2014.

YIN, R. K. Estudo de caso: planejamento e métodos. 2. ed. Porto Alegre: Bookman, 2001.

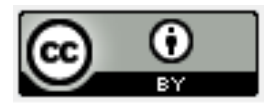

Artigo recebido em: 22/04/2019 e aceito para publicação em: 07/06/2020

DOI:http://dx.doi.org/10.14488/1676-1901.v20i2.3622 